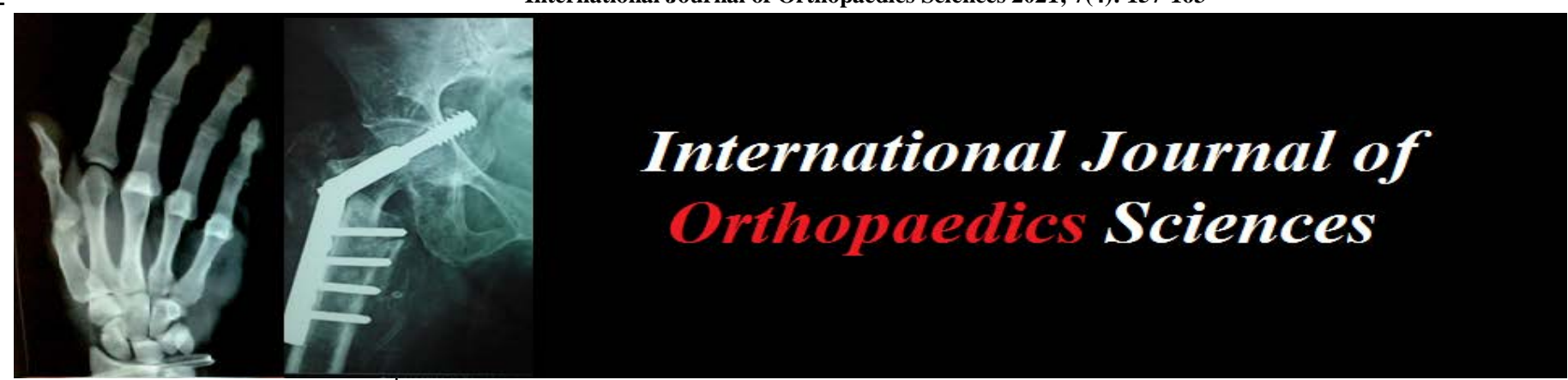

E-ISSN: 2395-1958

P-ISSN: 2706-6630

IJOS 2021; 7(4): 157-163

(C) 2021 IJOS

www.orthopaper.com

Received: 13-07-2021

Accepted: 03-09-2021

Dr. A Manoharan

Professor of Orthopaedics

Stanley Medical College,

Chennai, Tamil Nadu, India

\section{Dr. T Kalaiyarasan}

Assistant Professor of

Orthopaedics Stanley Medical

College, Chennai, Tamil Nadu,

India

Dr. Panneer Selvam VMS

Post Graduate, Stanley Medical

College, Chennai, Tamil Nadu, India
Corresponding Author:

Dr. T Kalaiyarasan

Assistant Professor of

Orthopaedics Stanley Medical

College, Chennai, Tamil Nadu,

India

\section{A functional outcome of medial open wedge high tibial osteotomy for medial compartmental osteoarthritis knee: Prospective study}

\author{
Dr. A Manoharan, Dr. T Kalaiyarasan and Dr. Panneer Selvam VMS
}

DOI: https://doi.org/10.22271/ortho.2021.v7.i4c.2877

\section{Abstract}

Background: Knee osteoarthritis ranks among the most common disability in adults and the prevalence is projected to increase sharply over next two decades. The common problem is the medial compartment osteoarthritis of knee which leads to varus deformity and progresses to disability.

When the disease progresses high tibial osteotomy, unicompartmental arthroplasty and total knee arthroplasty are the surgical options used

Material and Methods: Twenty cases of medial joint osteoarthritis knee were operated by high tibial open wedge osteotomy fixed with 'T' plate between from April 2019 to November 2020

Results: The mean follow up period was 20 months. The results were analysed using visual analogue pain scale, knee society score, Japanese orthopaedic association knee rating scale. The outcome was excellent in $15 \%$, good in $65 \%$, fair in $15 \%$ and poor in $5 \%$ by Knee society score and outcome was excellent in $15 \%$, good in $70 \%$, fair in $10 \%$ and poor in $5 \%$ by JOA knee rating scale.

Conclusion: High tibial osteotomy is a good treatment of choice for medial compartment osteoarthritis of knee in the young individuals.

Keywords: Medial compartmental osteoarthritis of knee, High tibial osteotomy, knee society score

\section{Introduction}

Knee osteoarthritis is one of the most common disability in adults and the prevalence is projected to increase sharply over next two decades ${ }^{[1]}$.

The common problem is the medial compartment osteoarthritis of knee which leads to varus deformity and progresses to disability. The treatment options available are non-surgical in the early stage which includes weight loss, low impact activity and physiotherapy.

The surgical treatment options like high tibial osteotomy, unicompartmental arthroplasty and total knee arthroplasty are used when the disease progresses to end stages. For healthier patients older than 60 years arthroplasty is considered a good option with good long-term outcome but the concern is the longevity of the implants in younger patients ${ }^{[2]}$.

The acknowledged surgical technique for treatment of medial compartment arthrosis of knee in younger patients is High tibial osteotomy and the method of open wedge osteotomy procedure is more popular than closed wedge osteotomy because the peroneal nerve is not in jeopardy and there is no disruption of proximal tibiofibular joint and lateral collateral ligaments worth achievement of more precise correction ${ }^{[3]}$.

But the concerns are the Selection of appropriate patients, extensive pre-operative planning and accurate surgical technique which are essential for successful outcome. The biomechanical principle of high tibial osteotomy is to reallocate the weight bearing forces from the damaged medial compartment to the lateral compartment thus alleviating pain and slowing the disease progression ${ }^{[3]}$. The purpose of this study is to analyse the outcome of medial open wedge osteotomy in patients having unicompartmental osteoarthritis with varus deformity using the T locking plate.

\section{Materials and Methods}

In our study, All the physiologically young patients patients less than 60 years with the complaints of knee pain and on clinical examination suspected of medial unicompartmental 
osteoarthritis who were willing for surgery included in the study. Patients bicompartmental and tricompartmental osteoarthritis, Restricted range of movements at knee flexion less than 90 degrees, flexion contracture of more than 15 degrees, aged above 60 years, Deformity correction of more than 20 degree, post traumatic arthritis, Inflammatory arthritis have been excluded from the study.

With above mentioned criteria patients were selected and assessed preoperatively for deformity, range of motion, assessment $\mathrm{x}$-ray with 4 views including anteroposterior (AP) \& lateral views of the knee, axial view of the patellofemoral joint, and weight-bearing alignment view showing both lower extremities from hip to ankle scanogram and scores analysed using Japanese Orthopaedic Association Knee rating Scale, Knee society score, visual pain analogue scale.

The mechanical axis, anatomical axis and weight bearing axis measured in the alignment view which is used to determine the location, type, and amount of corrective osteotomy.

Usually 60 percentage of the body weight force passes through the medial compartment. Normal values include a $6^{\circ}$ of valgus between the mechanical and anatomical axes, and the weight bearing line passing through the lateral $30-40 \%$ of the tibial plateau. The symptoms of Isolated compartmental osteoarthritis appear when the alignment is more than 10 degree off of the normal range ${ }^{[4]}$

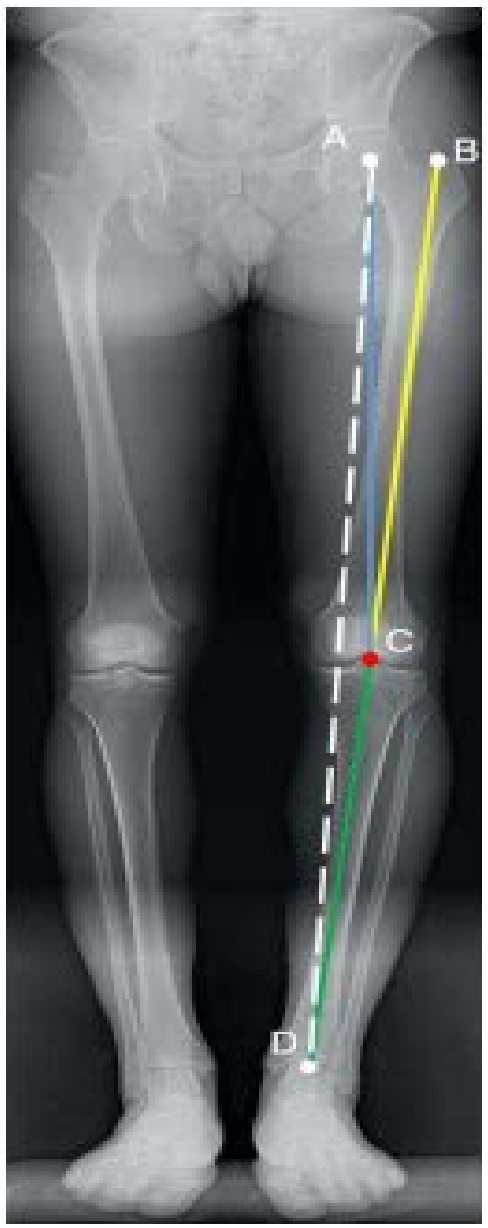

Fig 1: Mechanical and Anatomical axis

The Mechanical axis is the line drawn from the centre of the femoral head to the centre of the knee and from centre of knee to centre of ankle, normal value $-1-3^{\circ}$ varus $^{5}$

weight bearing axis is the line drawn from the centre of the femoral head to the centre of ankle joint Anatomical axis is the line from the piriformis fossa to the centre of the knee joint and a line through the long axis of the tibia, normal value- $5-7^{\circ}$ valgus ${ }^{[6]}$

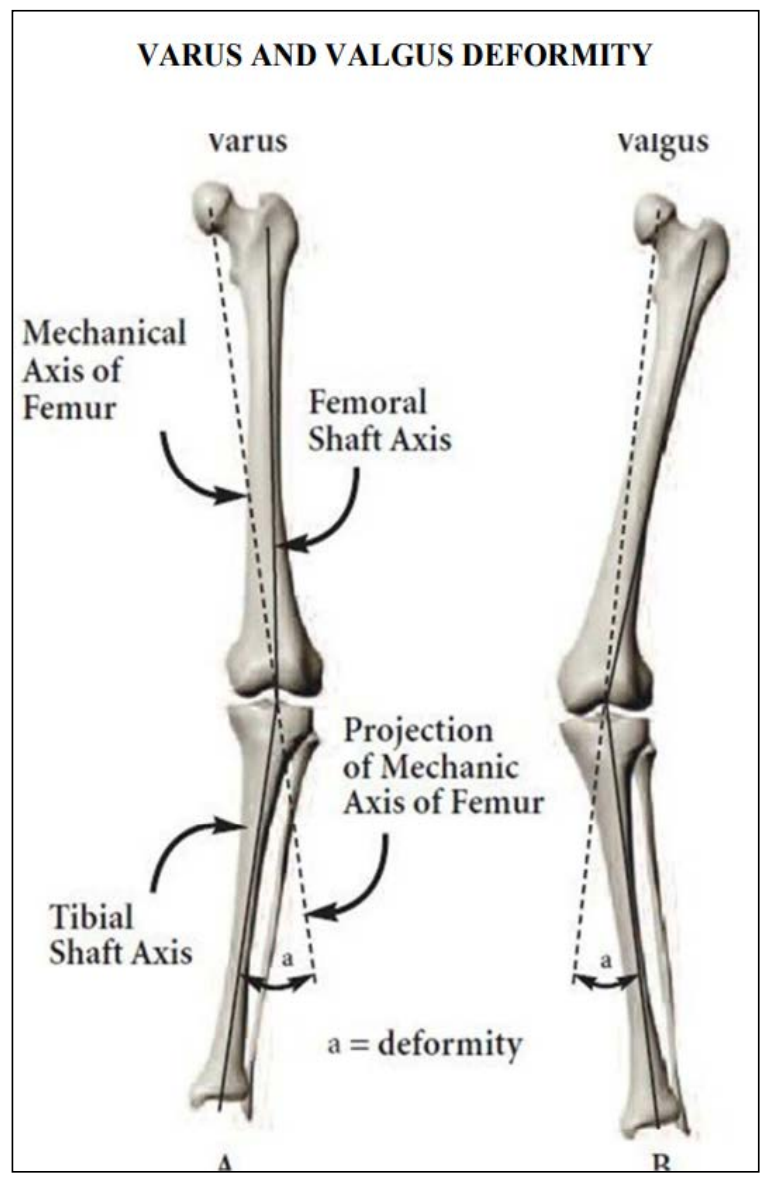

Fig 2: Deformity measurement

The deformity is calculated by the angle formed by the mechanical axis of femur with anatomical axis of tibia.

\section{Fujiswa Point ${ }^{[7]}$}

The angle of correction based on the research of Fujisawa et al \& later was adapted as a guideline to determine the pre \& postoperative amount of varus correction.

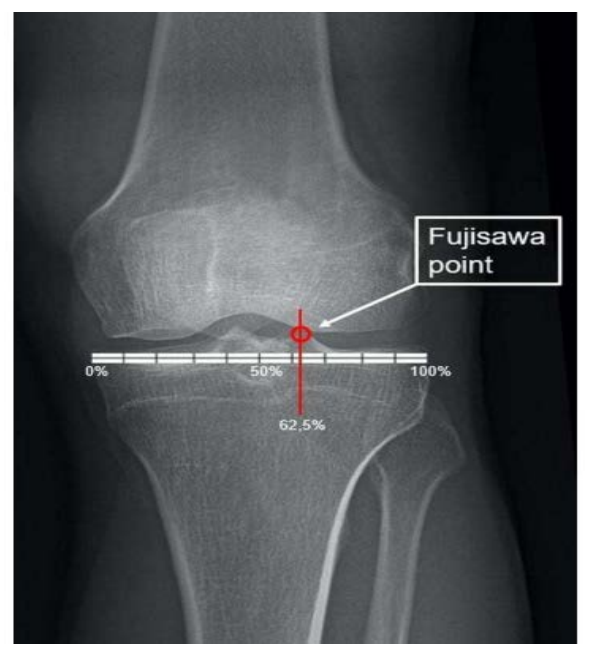

Fig 3: Fujisawa point

The weight bearing line should pass from 62.5 percentage of the tibial plateau width when measured from the edge of the medial tibial plateau. This point - called Fujisawa point matches over the mechanical axis with 3- 5degree valgus 
\&locates slightly lateral to the lateral tibial spine ${ }^{[4]}$.

\section{How to calculate deformity correction}

A line is drawn from Fujisawa point to the centre of the femoral head \& another to the centre of the ankle joint and the angle created by these two lines indicates the amount of correction Then the osteotomy line is drawn at about $4 \mathrm{~cm}$ below the medial joint line toward the fibular head. The width of the triangle's base (in millimetres) corresponds to the amount of correction necessary during a medial open wedge osteotomy The objective of valgus High tibial osteotomy is to attain a minor valgus axis to prevent the recurrence of varus. Nearly 810 degree of valgus in the anatomical axis or 3-5 degree of valgus in the mechanical axis are considered the optimal correction after surgery. Undercorrection of varus can result in recurrence of deformity whereas overcorrection can result in lateral compartment $\mathrm{OA}^{[8,9]}$.

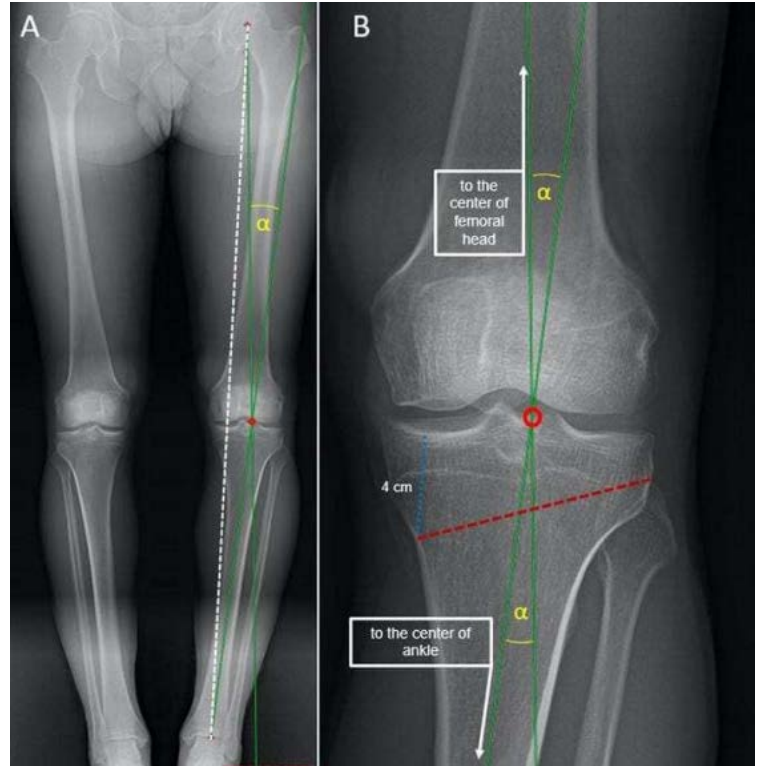

Fig 4: Deformity calculation

\section{Surgical Techniques ${ }^{[9]}$}

All the cases were operated under regional anaesthesia after proper preoperative planning, templating with proper informed consent.

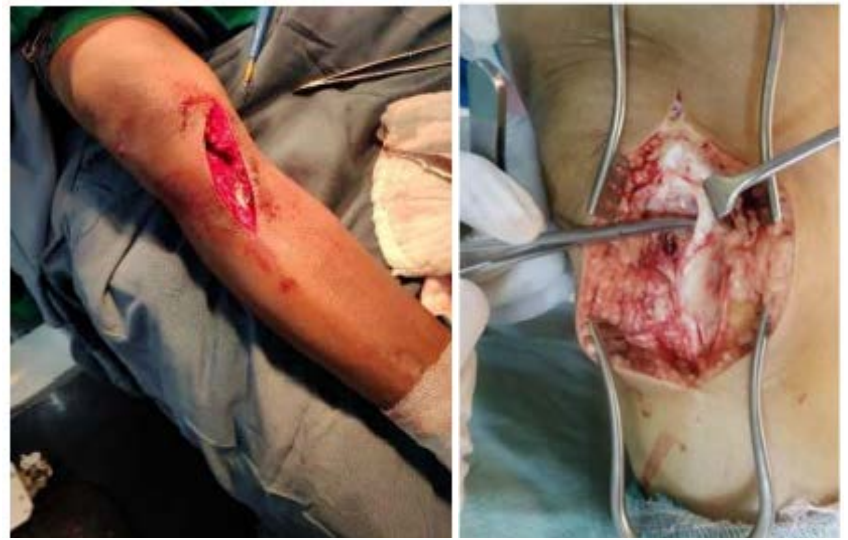

Fig 5: intra operative pictures

an incision is made in the midway between posteromedial border of the tibia \& medial aspect of the tibial tuberosity. A 3-5 cm longitudinal skin incision is made carefully by beginning 1-2 $\mathrm{cm}$ inferior to the medial joint line and continuing caudally to the pes anserinus.
After dividing the sartorial fascia, we usually distract the tendons of pes anserinus distally, but an inverted L-shaped flap can also be elevated.

After subperiosteal dissection and sufficient exposure of the proximal-medial tibia and the joint line, the superficial medial collateral ligament (sMCL) fibers are elevated from their medial tibial attachment sides; otherwise, if the attachment of sMCL is left intact on the medial tibia, pressures of the medial compartment may inevitably increase as a result of the tensioning of sMCL fibers during the distraction phase of the osteotomy. Proximal to the tibial tubercule, patellar tendon should be identified and protected from the possible damage that might be caused by the blade of the saw by placing a broad retractor anteriorly. It is of high importance to conduct careful subperiosteal dissections in order to protect and secure the posterior neurovascular structures.
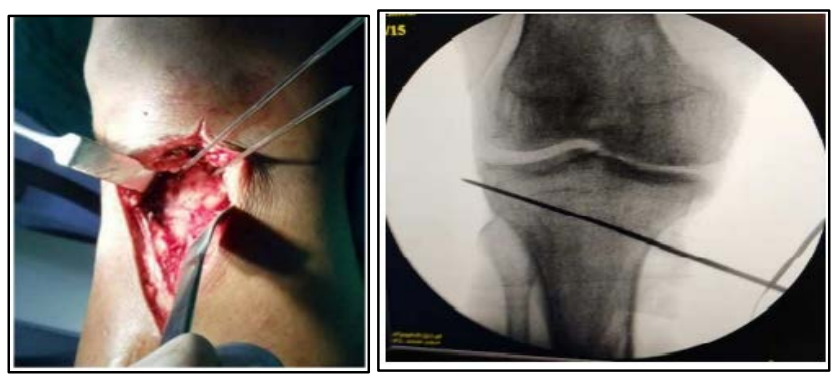

Fig 6: Guide wire placement

After the subperiosteal dissection and exposure of the entire proximal-medial portion of the tibia, a guide wire is inserted, starting proximal to the tibial tubercule and aiming toward thetip of the fibular head with an anteromedial to posterolateral trajectory. After the insertion of the first guide wire, it is optional to place another wire posteriorly to determine the osteotomy's sagittal angle that can influence the amount of the sagittal slope.

If a reduction of the posterior tibial slope is desired, the posterior guide wire should be placed more superiorly resulting in a flatter cut. If a rise of the sagittal slope is desired, then the posterior guidewire should be placed more inferiorly.
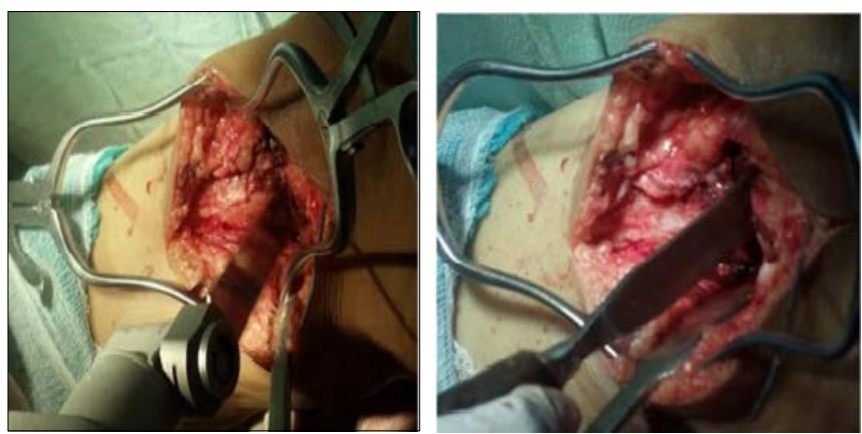

Fig 7: Osteotomy

An oscillating saw is used to make the first cut of the osteotomy on the anteromedial cortex. This cut is advanced with osteotomes until to a distance of $1-1.5 \mathrm{~cm}$ to the lateral cortex of the tibia, in order not to cause any fracture on the tibial plateau. In addition to that, it is also recommended, that the vertical distance from the tip of the osteotome to the lateral tibial plateau should be 1.25 times of the horizontal distance to the 42 lateral tibial cortex, to minimize the risk of any fracture on the lateral tibial plateau. 

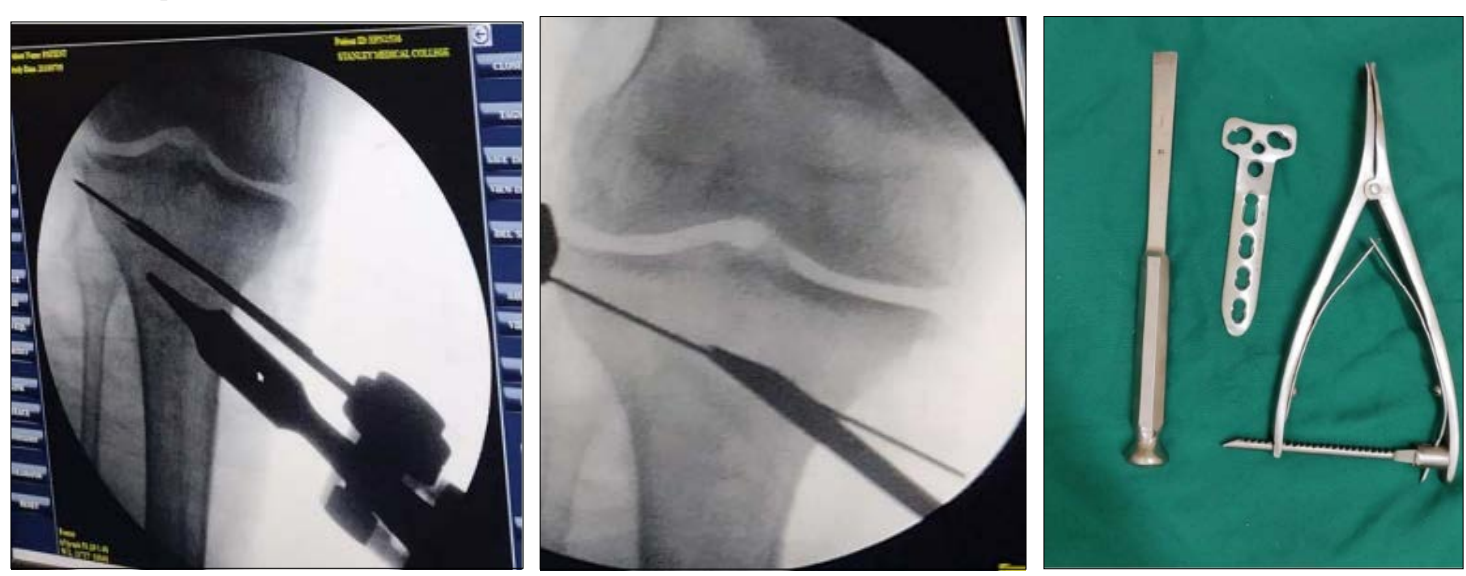

Fig 8: $\mathrm{C}$ arm and instruments

Hereby, the osteotomy is ended, followed by the opening of the osteotomized bone and very gentle and careful application of valgus force on the tibia. Osteotomy side is opened sequentially with calibrated wedges. As a result of that, a new mechanical axis has been reconstructed. The new mechanical axis is confirmed by either placing a cord of electrocautery or a long alignment rod from the centre of the hip to the centre of the ankle or confirming its distance from the knee joint under image intensifier. It was also suggested to add a concomitant tibial tuberosity osteotomy, if more than $12.5 \mathrm{~mm}$ correction is required, in order to avoid the potentially adverse effects of patella baja and increased pressure in patellofemoral compartment.

Precontour T Plate to fit the medial proximal tibia, eliminating the need for intraoperative contouring and reducing soft tissue irritation. Autogenous iliac bone graft is considered in patients who are at risk of non-union such as smokers \& obese patients because Results were much better with lower complications than in allograft and bone substitutes such as the calciumphosphate ceramic spacer. The postoperative rehabilitation mainly depends on the rigidity of the fixation. Patients with plate fixators are allowed to start partial weight bearing (15$20 \mathrm{~kg}$ ) immediately after surgery subjected to the amount of pain \& wound healing but full weight bearing is allowed only after four weeks after surgery ${ }^{[8]}$. All the patients had regular follow up and analysed with $\mathrm{x}$ ray and scoring as per protocol.

\section{Results}

In our study total number of patients were twenty among them 12 were female, 8 were male, average was nine years, 14 cases were left sided and 6 were right sided. Preoperatively, about 18 cases had 5-9 degree of varus deformity and 2 cases had 10-15 degree deformity. and About 65\% had good Knee society score, $15 \%$ had excellent score, another $15 \%$ had fair score and $5 \%$ had poor score.

Based on Japanese Orthopaedic Association Knee Rating Scale About $70 \%$ had good score,15\% had excellent score,10\% had fair score and $5 \%$ had poor score.

Bone grafting was not done in 12 knees and good bone consolidation started in 3 months laterally and progressed to the medial side in 1 year. There were no cases of implant failure or hardware prominence. one patient had superficial skin infection which settled with appropriate antibiotics Japanese Orthopaedic Association - Knee rating scale for clinical evaluation of osteoarthritis of the knee

\begin{tabular}{|l|l|}
\hline Pain (30 points) & 30 \\
\hline No pain at any time & 20 \\
\hline Mild starting pain & 10 \\
\hline Moderate pain on walking & 5 \\
\hline Severe pain on walking & 0 \\
\hline Severe pain at rest & 20 \\
\hline Function (20 points) & 15 \\
\hline Walking unlimited & 10 \\
\hline Walking distance of 0.5 to $1 \mathrm{~km}$ & 5 \\
\hline Walking less than $0.5 \mathrm{~km}$ & 0 \\
\hline Walking only indoors & 10 \\
\hline Cannot walk & 20 \\
\hline Range of motion (20 points) & 15 \\
\hline More than $120^{\circ}$ & \\
\hline $119^{\circ}-90^{\circ}$ & \\
\hline $89^{\circ}-60^{\circ}$ & \\
\hline $59^{\circ}-30^{\circ}$ & \\
\hline
\end{tabular}

\begin{tabular}{||l|c|}
\hline \multicolumn{2}{|l|}{ Flexion deformily (10 points) } \\
\hline $0^{\circ}-10^{\circ}$ & 10 \\
\hline $11^{\circ}-30^{\circ}$ & 0 \\
\hline More than $30^{\circ}$ & \\
\hline Varus or valgus deformity (10 points) & 10 \\
\hline Less than $5^{\circ}$ & 5 \\
\hline $6^{\circ}-15^{\circ}$ & 0 \\
\hline More than $15^{\circ}$ & \\
\hline Activitics of daily living (10 points) & \\
\hline Rising from chair & \\
\hline Climbing stairs & \\
\hline Going downstairs & \\
\hline Onc foot standing & \\
\hline Running & \\
\hline (2 points for easy; 1 point, difficult; 0 points, impossible in each item) \\
\hline
\end{tabular}

Table 1: Knee society score 


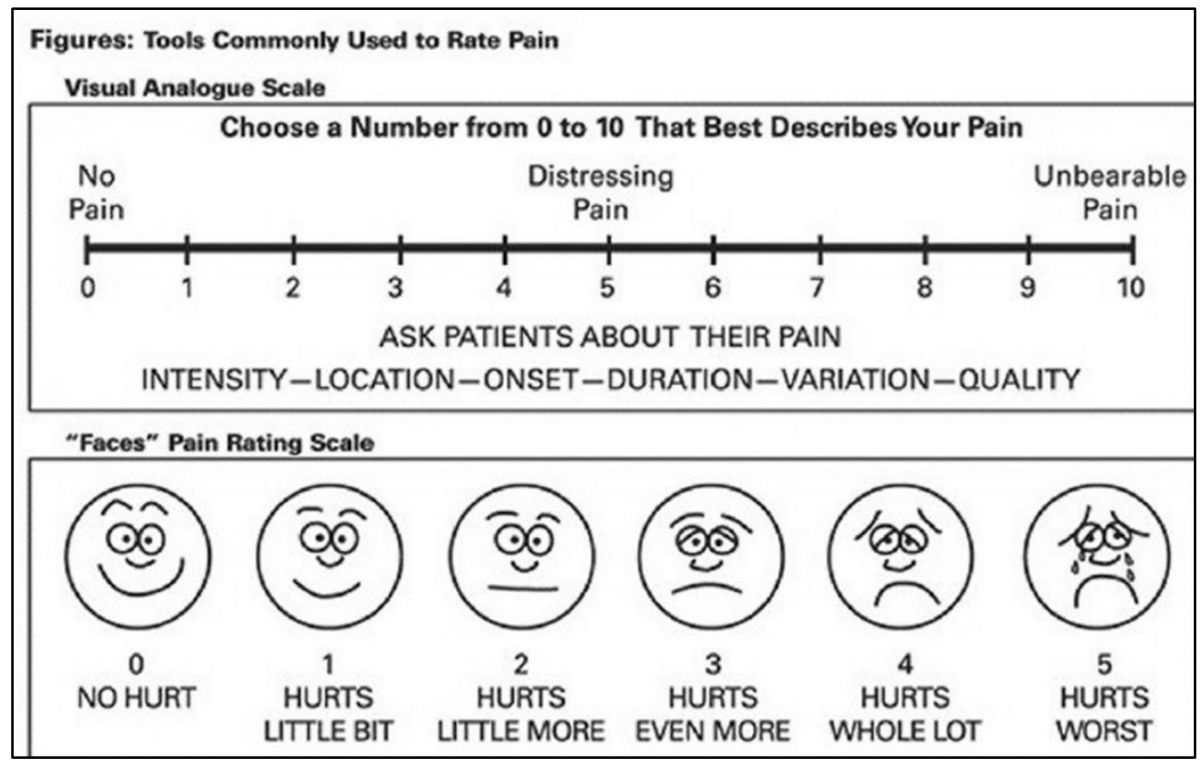

Fig 9: Visual analogue scale

\section{Case Illustrations}

Case 1:

51 years male with knee pain for $1^{1 / 2}$ years Preoperative varus deformity - 9 degrees Deformity to be corrected- 15 degrees

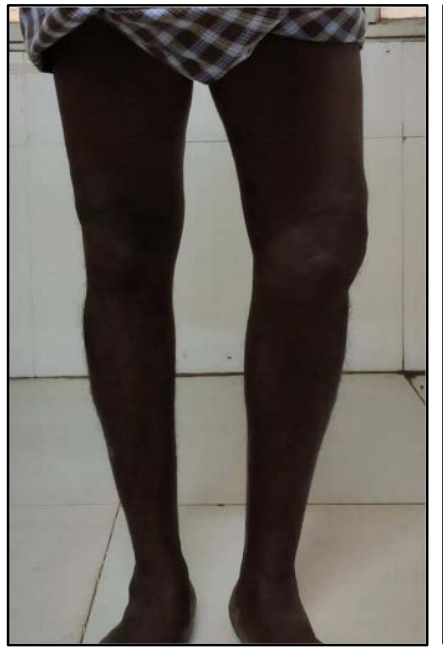

Fig 10: case demonstration
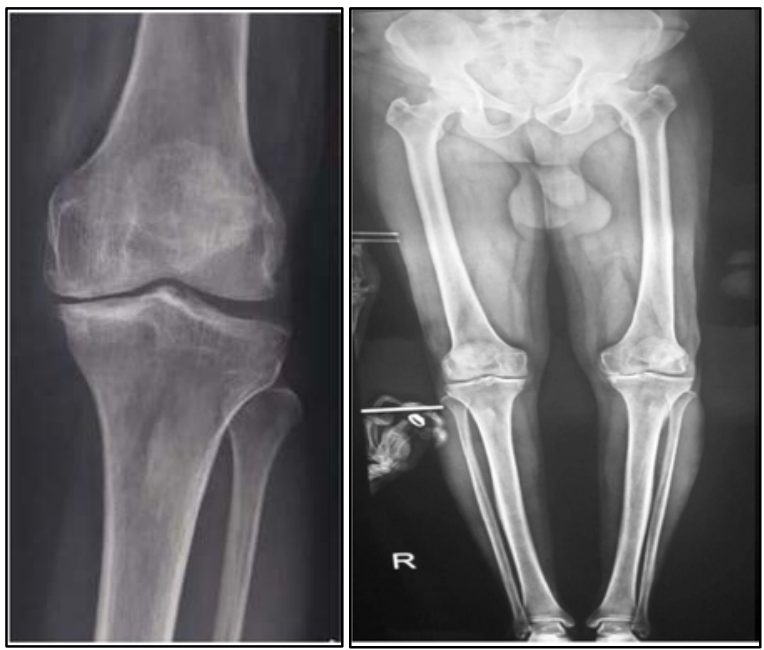

Fig 11: Standing full $x$-ray

Post-operative follow up

3 months
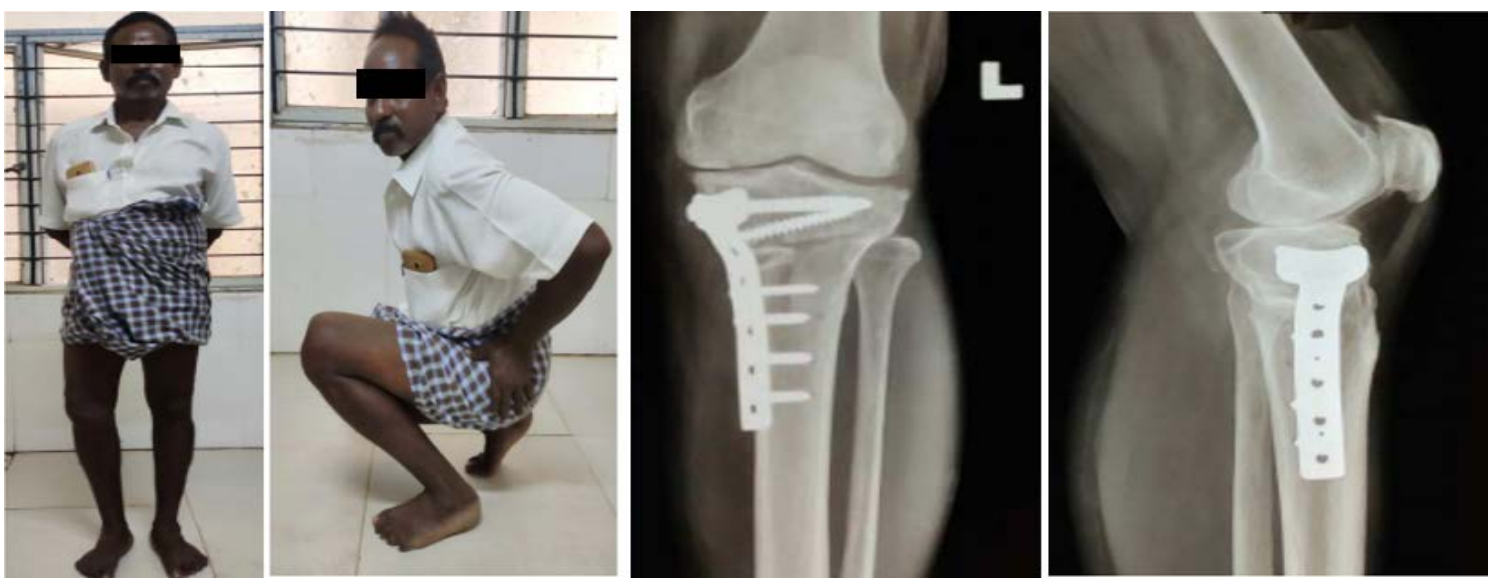

Fig 13: Post-operative pictures 


\section{8 months}

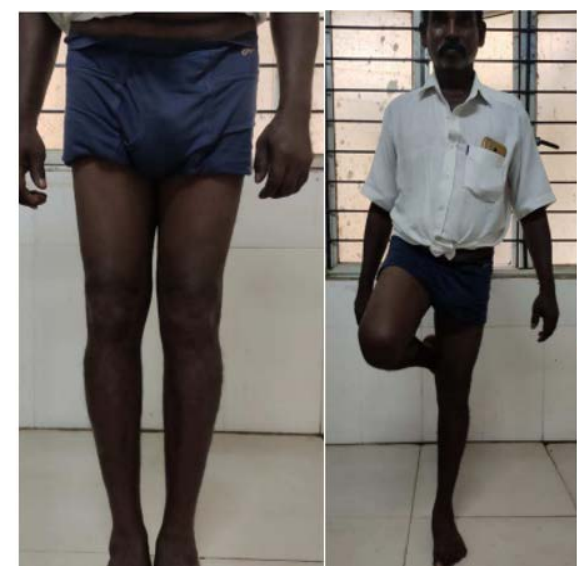

Fig 14: Follow up

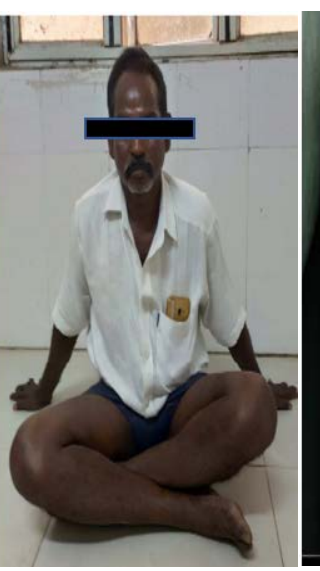

Table 2: Functional scores

\begin{tabular}{|c|c|c|c|}
\hline & Pain scale & Knee society score & Joa knee scoring \\
\hline Pre-operative & 7 & 60 & 57 \\
\hline Post-operative & 2 & 90 & 81 \\
\hline
\end{tabular}

\section{Case 2}

49/F presented with Pain in Right knee -3 yrs

Varus deformity - 14 degrees

Correction required - 19 degrees

Preoperative- 15 degrees

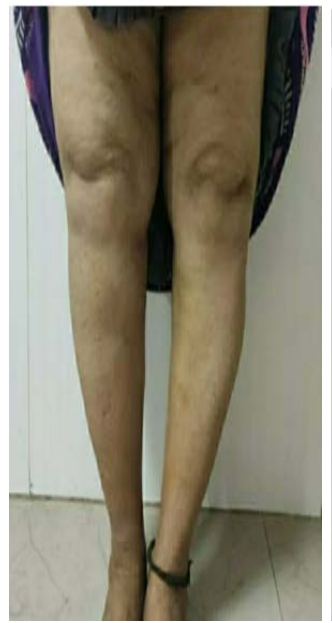

Fig 15: Preoperative pictures

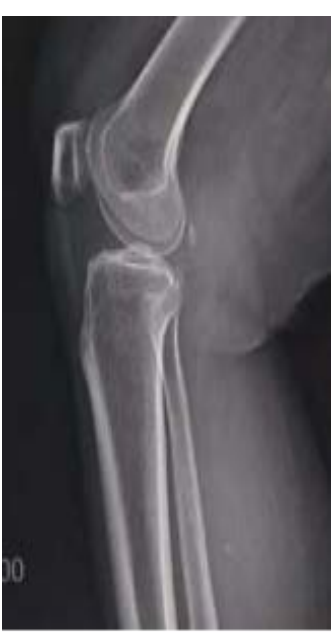

res
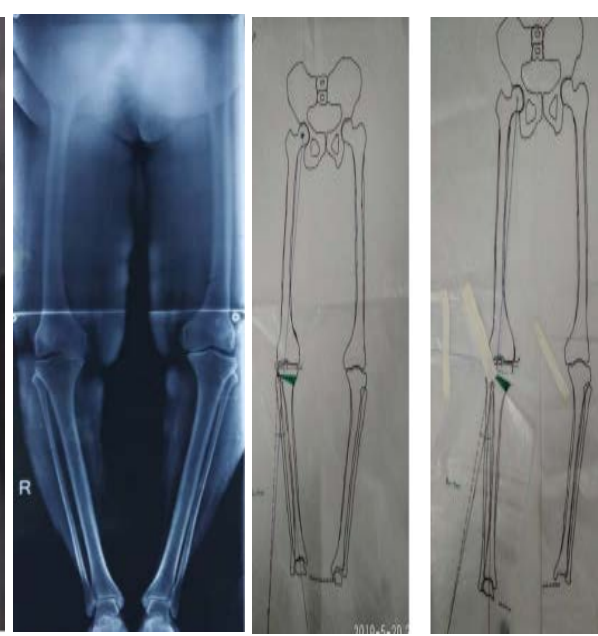

Fig 16: Standing $x$ ray and templating

\section{Post-operative-3 months}

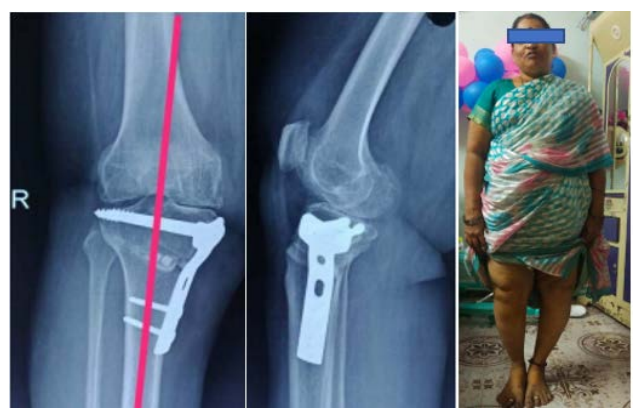

Fig 18: Post-operative pictures

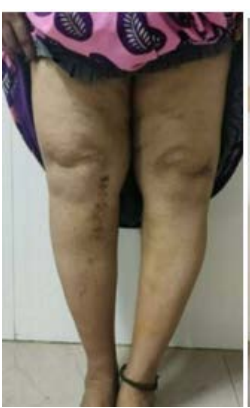

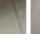

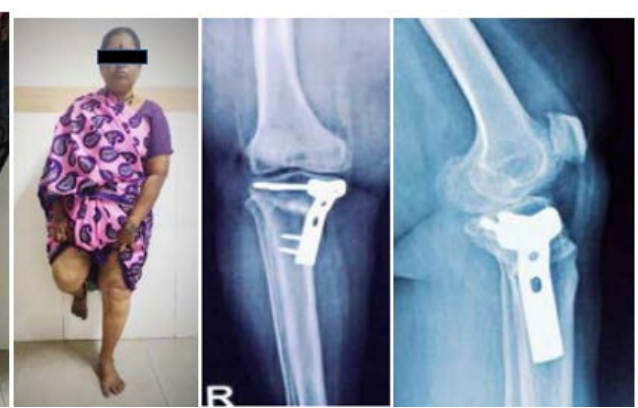

Fig 19: Follow up 


\section{Post-operative - 18 months}

Table 3: Functional scores

\begin{tabular}{|c|c|c|c|}
\hline & Pain scale & Knee society score & Joa knee scoring \\
\hline Pre-operative & 7 & 60 & 54 \\
\hline Post-operative & 2 & 84 & 80 \\
\hline
\end{tabular}

\section{Discussion}

High tibial osteotomy is a time tested procedure in the treatment of medial compartment osteoarthritis of knee. Total knee replacement or unicompartmental knee replacement are not suitable in young healthy active patients with good functional activities. Our study mainly aimed to analyze the short term and long term results of the surgery in our patients and its possible role in our social context. The main complaint for which our patients opted for surgery in our study is the intolerable pain and the disability causing restrictions in day to day activities.

In medial compartment osteoarthritis due to shifting of the weight bearing on the medial side of the knee will result in more cartilage destruction and subsequently varus deformity. Therefore, a unicompartmental knee replacement will not correct the alignment. A corrective osteotomy to alter the weight bearing axis will be ideal to slow down the degenerative process ${ }^{[10-12]}$.

Raymond H.Kim has specified that osteotomy is a better option when considering active young patients ${ }^{[13]}$.

Song et al assessed the outcome of 104 lateral closing wedge and 90 medial opening wedge osteotomies and they found that the latter had slightly lesser complication ${ }^{[14]}$.

Luites et al in their study stated that both types of osteotomies had equal fixation stability, pain relief ${ }^{[15]}$.

Koshino et al studied the effectiveness of high tibial osteotomy using porous hydroxyapatite as a wedge and found that it gave good results and prevents collapse, but this was not a comparative study. Bone grafts and substitutes are usually not necessary and we have observed that the patients in our study without bone grafting also had good consolidation ${ }^{[16]}$.

The results seen in this study are comparable with results of Kolb et al. ${ }^{[17]}$ and Sen et al. ${ }^{[18]}$, but it also has limitations like it is not a comparative study and the sample size of the study is small. As stated by Sen et al, long term studies are lacking in high tibial osteotomies and are necessary for more clear idea about the outcome. But this short term study shows that osteotomy of the knee is definitely a viable option in unicompartmental osteoarthritis of the knee.

\section{Conclusion}

High tibial osteotomy is a good procedure of choice for the treatment of medial compartment osteoarthritis of knee in the young individuals.

Appropriate patient selection, good pre-operative planning and precise surgical techniques are essential for successful results.

\section{References}

1. Lawrence RC, Felson DT, Helmick CG, Arnold LM, Choi $\mathrm{H}$, Deyo RA et al. Estimates of the prevalence of arthritis and other rheumatic conditions in the United States: Part II. Arthritis \& Rheumatism 2008;58(1):26-35.

2. Coventry MB. Osteotomy about the knee for degenerative and rheumatoid arthritis. J Bone Joint Surg Am. 1973;55(1):23-48. [PubMed] [Google Scholar]

3. Akamatsu Y, Koshino T, Saito T, Wada J. Changes in osteosclerosis of the osteoarthritic knee after high tibial osteotomy. Clin OrthopRelat Res 1997;334:207-14.
[PubMed] [Google Scholar]

4. Leutloff D, Tobian F, Perka C. High tibial osteotomy for valgus and varus deformities of the knee. Int Orthop. 2001;25(2):93-6. [PMC free article] [PubMed] [Google Scholar]

5. MAA. Amis, "Biomechanics of high tibial osteotomy," Knee Surgery, Sports Traumatology, Arthroscopy, 2013;21(1):197-205, View at: Publisher Site | Google Scholar

6. Uquillas C, Rossy W, Nathasingh CK, Strauss E, Jazrawi L, Gonzalez-Lomas G. “Osteotomies about the knee,” The Journal of Bone and Joint Surgery-American 2014;96(24):e199, View at: Publisher Site | Google Scholar

7. Fujisawa Y, Masuhara K, Shiomi S. The effect of high tibial osteotomy on osteoarthritis of the knee. An arthroscopic study of 54 knee joints. Orthop Clin North Am 1979;10(3):585-608. [PubMed] [Google Scholar]

8. Miniaci A, Ballmer FT, Ballmer PM, Jakob RP. Proximal tibial osteotomy. A new fixation device. Clin OrthopRelat Res 1989;246:250-9. [PubMed] [Google Scholar]

9. Lobenhoffer P, Agneskirchner JD. Improvements in surgical technique of valgus high tibial osteotomy. Knee Surg Sports Traumatol Arthrosc 2003;11(3):132-8. [PubMed] [Google Scholar]

10. Medial open wedge osteotomy using puddu plate for unicompartmental osteoarthritis of knee Balu C Babu and Venu Madhav HV. International Journal of Orthopaedics Sciences 2016;2(2):109-112.

11. Lobenhoffer P, Agneskirchner JD. Improvements in surgical technique of valgus high tibial osteotomy. Knee Surg Sports Traumatol Arthrosc 2003;11(3):132-8. [PubMed] [Google Scholar]

12. Daniel Goutallier PR, Stéphane Van Driessche, Olivier Manicom, Edy Sari Ali, Jacques Bernageau, Catherine Radier. Influence of Lower-Limb Torsion on Long-Term Outcomes of Tibial Valgus Osteotomy for Medial Compartment Knee Osteoarthritis: JBone Joint Surg 2006;88-A(11):2439- 2447.

13. Kelly MA, Kim RH et al. The new arthritic patient and non arthroplasty treatment options. J bone joint Surg Am. 2009;91(5):40-42.

14. Song et al. The complications of high tibial osteotomy. J bone joint surg (Br)2010;92B:1245-52

15. Leuites et al. Fixation of opening versus closed wedge high tibial osteotomy. J bone joint surg (Br) 2009;91B:1459-65.

16. Koshino T, Murase T, Saito T. Medial opening-wedge high-tibial osteotomy with use of porous hydroxyapatite to treat medial compartment osteoarthritis of the knee. J Bone Joint Surg Am 2003;85-A:78-85.

17. Werner Kolb, Hanno Guhlmann, Christoph Windisch, Heiko Koller, Paul Grützner, Klaus Kolb. Opening Wedge High Tibial Osteotomy with a Locked Low-Profile PlateSurgical Technique: JBJS 2009;91-A(11):2581-2588.

18. Song et al. The complications of high tibial osteotomy. J bone joint surg (Br)2010;92B:1245-52. 